\title{
CD133/EpCAM Cancer Stem Cell Markers of Tumour Stage in Colorectal Cancer Cells
}

BL Milner ${ }^{1 *}$, CB Penny1, VE Gibbon ${ }^{2}$, P Kay $^{3}$ and P Ruff ${ }^{1}$

${ }^{1}$ Department of Internal Medicine, Faculty of Health Sciences, University of the Witwatersrand, 7 York Road, Parktown, Johannesburg, South Africa ${ }^{2}$ Department of Anthropology, Faculty of Arts, University of New Brunswick, 13 Mac Aulay Lane, Fredericton, NB, Canada

${ }^{3}$ Department of Surgery, Faculty of Health Sciences, University of the Witwatersrand, 7 York Road, Parktown, Johannesburg, South Africa

\begin{abstract}
In solid tumours, a discreet population of tumour associated cancer stem cells (CSCs) are proposed to drive and sustain tumour development and be responsible for tumour relapse. Colorectal cancer stem cells express cellspecific surface markers, including amongst others, CD133, EpCAM, CD44, CD166, and CD94f. In the present study, we characterised cell populations in the human colon adenocarcinoma cell lines, SW1116, HT29 and DLD1, expressing both CSC markers CD133 and EpCAM. These cell lines represent early, mid and late stages of colorectal tumours, respectively. Up to $10^{7}$ SW1116, HT29 and DLD1 cells, co-stained with anti-CD133 and anti-EpCAM, were evaluated using flow cytometry. We report here progressively increasing proportions of cells co-expressing the CD133/EpCAM epitopes in the respective cell lines. In the SW1116 cell line, $2.42 \pm 0.20$ percent of cells were CD133+EpCAM+, in the HT29 cell line, $5.13 \pm 0.17$ percent of cells were CD133+EpCAM+, and in the DLD1 cell line, $10.30 \pm 0.2$ percent of cells were CD133+EpCAM+. These data suggest the frequency of CD133/EpCAM marker expression may be associated with tumour stage and aggression.
\end{abstract}

Keywords: CD133; EpCAM; Colorectal cancer; Colon cancer stem cells; Flow cytometry

\section{Introduction}

Colorectal cancer is ranked globally as the third most diagnosed cancer, and as a leading cause of cancer-related deaths [1]. In recent years, it has been hypothesised that cancer stem cells are the basis for both the development of solid tumours and their continuance. It is suggested by the cancer stem cell (CSC) model that a unique subgroup of tumour resident cells are pluripotent and can give rise to the heterogeneous cell populations that constitute a tumour, through continued cycles of self-renewal and differentiation [2-4]. Stem cells isolated from colorectal cancer express a number of stem cell-specific surface markers, including amongst others, CD133, Epithelial cell adhesion molecule (EpCAM), CD44, CD166, and CD94f [4,5]. In the present study, CD133 and EpCAM expression were evaluated in colorectal adenocarcinoma cell lines, representative of early, mid and late stage colorectal tumours.

Besides being a marker for colorectal cancer stem cells, CD133 has been identified as a stem cell marker in a number of other solid tumours, including brain, liver, ovarian, lung, pancreas, prostate and skin cancers [6-8]. CD133 is a pentaspan trans-membrane protein that is detected by an antibody binding to its two glycosylated extracellular moieties $[9,10]$. Whilst its function is not clearly understood, this glycoprotein is localised to cell membrane protrusions and microvilli, where it associates with cholesterol domains, suggesting a functional role in membrane transport processes $[11,12]$.

Similarly, to CD133, EpCAM or CD326 is a trans-membrane protein expressed in epithelial cells, having both extracellular and intracytoplasmic domains, but with a single trans-membrane domain; and the extracellular domain containing two EGF-like repeats [13]. Functionally, it is associated with the regulation of calcium independent, cadherin mediated homophilic cell adhesion. EpCAM originally identified as a highly expressed cell surface marker on human colon carcinoma cells is also associated with a number of other rapidly proliferating carcinomas [14]. Moreover, raised expression levels of EpCAM have been linked with cellular de-differentiation and proliferation of tumour cells [15] with an associated increase in oncogenic $c-m y c$ expression [16].
As evidence indicates that CSCs are metastatic, highly drug resistant, and cause tumour relapse even after chemotherapy, they therefore present as novel targets in cancer therapy [2,17]. In the present study, the likely presence of CSC populations are evaluated in human adenocarcinoma cell lines originally established from early, mid- and late stage colon cancers, respectively. Here using flow cytometry, the co-expression of two cancer stem cell surface markers, CD133 and EpCAM are assessed in cells derived from each of the SW1116, HT29 and DLD1 cell lines. In this study, we hypothesise that the expression of these two cancer stem cell markers CD133 and EpCAM, increase with metastatic stage.

\section{Materials and Methods}

\section{Cell lines}

The SW1116 cell line (ATCC, donated by Dr J. Magré, INSERM) was originally isolated from a 73 year old Caucasian male and represents a Dukes' stage A (stage I) colon cancer. The HT29 (ATCC, Manassas, United States), microsatellite-stable cell line was derived from a 44 year old Caucasian female and is Dukes' stage B (stage II) [18]. The Dukes' stage C (stage III) DLD1 cell line (HSSRB, Osaka, Japan) was isolated from an adult male and is microsatellite-unstable, with inactivating APC mutations [19].

Each cell line was cultured in Dulbecco's Modified Eagle's Medium:Hams F12 (DMEM:F12, Invitrogen, Carlsbad, United States), supplemented with $10 \%$ foetal bovine serum (FBS, Invitrogen,

*Corresponding author: BL Milner, Department of Internal Medicine, Faculty of Health Sciences, University of the Witwatersrand, 7 York Road, Parktown, Johannesburg, South Africa 2193, Tel: +27 11488 3621; Fax: +27 11643 8777; E-mail: brenda.wits@gmail.com

Received June 03, 2014; Accepted November 25, 2014; Published November 28,2014

Citation: Milner BL, Penny CB, Gibbon VE, Kay P, Ruff P (2014) CD133/EpCAM Cancer Stem Cell Markers of Tumour Stage in Colorectal Cancer Cells. J Tissue Sci Eng 6: 143. doi:10.4172/2157-7552.1000143

Copyright: $\odot 2014$ Milner BL, et al. This is an open-access article distributed under the terms of the Creative Commons Attribution License, which permits unrestricted use, distribution, and reproduction in any medium, provided the original author and source are credited. 
Citation: Milner BL, Penny CB, Gibbon VE, Kay P, Ruff P (2014) CD133/EpCAM Cancer Stem Cell Markers of Tumour Stage in Colorectal Cancer Cells. J Tissue Sci Eng 6: 143. doi:10.4172/2157-7552.1000143

Page 2 of 4

Carlsbad, United States) and $10000 \mathrm{U} / \mathrm{ml}$ penicillin with $10000 \mu \mathrm{g} /$ $\mathrm{ml}$ streptomycin (Lonza, Basel, Switzerland). The cells were incubated at $37^{\circ} \mathrm{C}$ with an atmosphere of $5 \% \mathrm{CO}_{2}$ and $90 \%$ humidity and were passaged at $70 \%$ confluency, every $2-3$ days.

\section{Antibodies}

Anti-CD133/2 (293C3-PE, 50 $\mu \mathrm{g} / \mathrm{ml})$ was obtained from Miltenyi Biotec (Bergisch Gladbach, Germany) and anti-EpCAM (FITC, $3 \mu \mathrm{g} /$ ml) from BD Biosciences (Franklin Lakes, United States). The AC133 epitope was used here since it and not the CD133 protein specifically identifies colon cancer stem cells [20].

\section{Flow Cytometry}

Up to $10^{7}$ SW1116, HT29 and DLD1 cells were re-suspended in $80 \mu$ l of a PBS solution (Sigma Aldrich, St. Louis, United States) containing 2mM EDTA (Sigma Aldrich, St. Louis, United States) and $0.5 \%$ bovine serum albumin (Sigma Aldrich, St. Louis, United States), $20 \mu \mathrm{l} \mathrm{FcR} \mathrm{blocking} \mathrm{reagent} \mathrm{(Miltenyi} \mathrm{Biotec,} \mathrm{Bergisch} \mathrm{Gladbach,}$ Germany), $10 \mu \mathrm{l}$ CD133/2 antibody (PE) and 20 $\mu$ EpCAM antibody
(FITC), respectively. The cells were incubated in the dark at $4^{\circ} \mathrm{C}$ for 20 minutes. Unstained cells served as a gating control and single stained cells served as compensation controls. The cells from each cell line were washed in $2 \mathrm{ml}$ of buffer, and centrifuged for 10 minutes at $300 \mathrm{~g}$. Next, the cells were re-suspended in a suitable amount of buffer and 50000 events were acquired on a BD LSR Fortessa flow cytometer (La Jolla, United States). The acquired data was analysed using "FlowJo" analysis software (version 9.4.11, TreeStar). To exclude doublets from singlets, the cells were gated on a forward scatter-area versus forward scatter-height graph and the singlets were further gated on a forward scatter-area versus side scatter-area graph. The results are presented as a proportion of cells, which is independent of the original sample size (see Figure 1). The experiment was repeated a further two times $(\mathrm{N}=3)$ using independent cell cultures.

\section{Statistics}

Microsoft Office Excel, 2007 was used for statistical analyses and cells expressing both surface markers were represented in bar graphs as means \pm the standard deviation (SD) (95\% CI).

\section{UNSTAINED CELLS}

\section{STAINED CELLS}
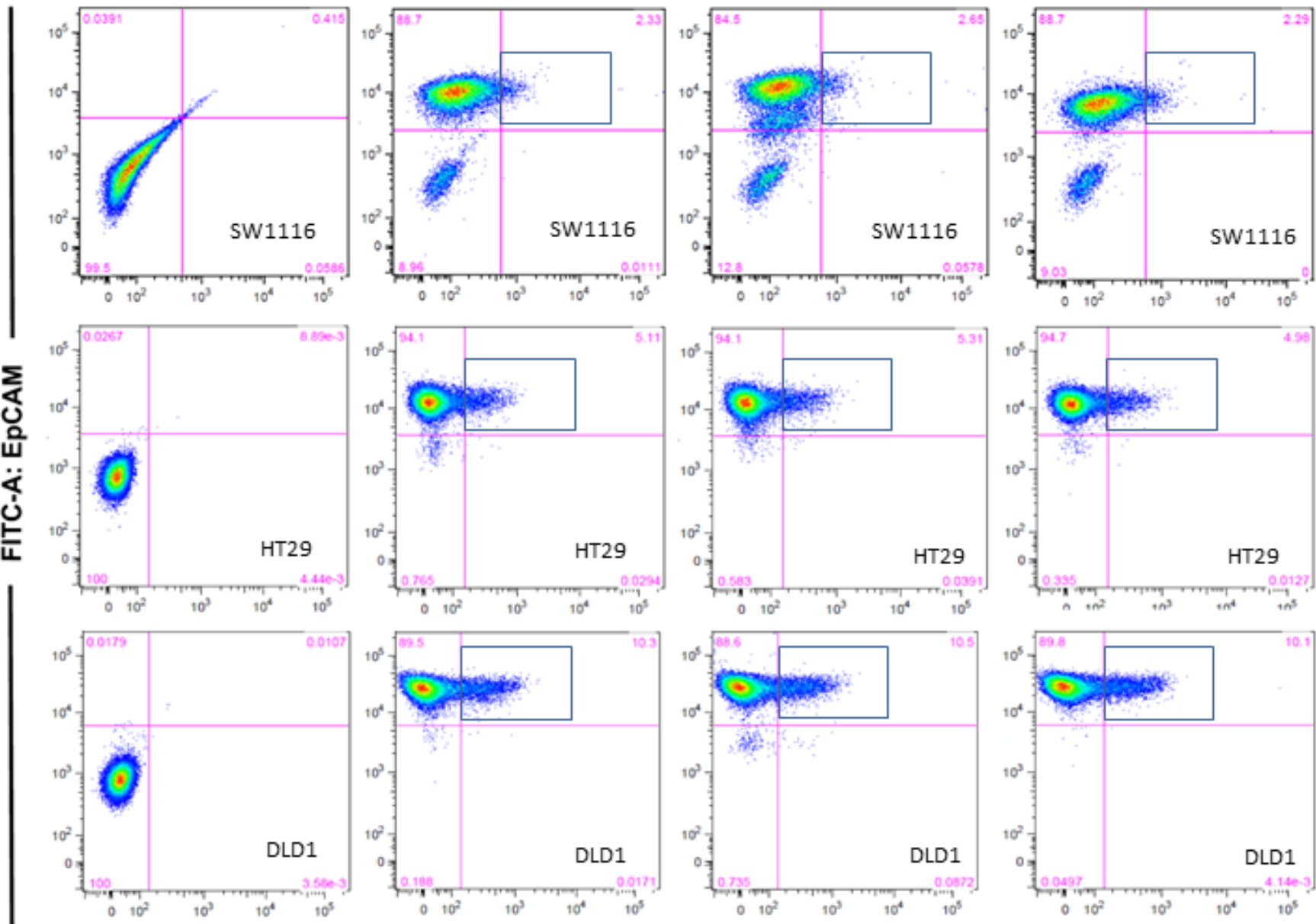

PE-A: CD133

Figure 1: Dot plots showing increasing co-expression of CD133 and EpCAM in SW1116 (Dukes' stage A), HT29 (Dukes' stage B) and DLD1 (Dukes' stage C) cell lines. Cells co-expressing CD133 and EpCAM (upper right quadrants in each stained dot plot) may represent CSC populations. Unstained cells were used to position quadrant gates (left column of dot plots) for each cell line and co-expression of CD133 and EpCAM was determined by staining with anti-CD133 (PE) and anti-EpCAM (FITC) antibodies. Each cell line was stained in triplicate. 


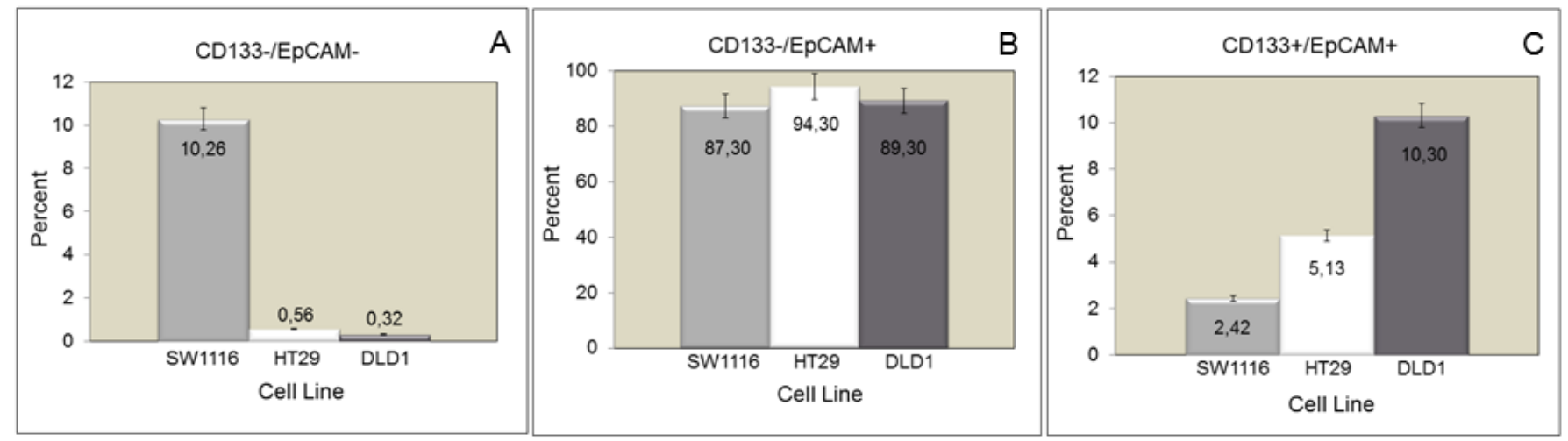

Figure 2: Flow cytometry analysis of CD133/EpCAM expression in SW1116, HT29 and DLD1 cells. The mean percentage of CD133-EpCAM- (A), CD133-EpCAM+ (B)

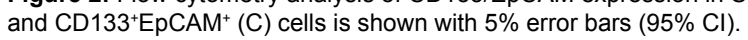

\section{Results}

The CD133/2 and EpCAM antibodies that recognise the CD133 and EpCAM epitopes respectively, were used to detect surface marker expression of CD133 and EpCAM in SW1116, HT29 and DLD1 cells. The unstained SW1116 cells were 99.5\% negative for CD133 and EpCAM expression, and the unstained HT29 and DLD1 cells were $100 \%$ negative for CD133 and EpCAM. The slight detection CD133 and EpCAM positive cells within the unstained SW1116 population most likely relates to the high levels of autofluorescence detected in this cell line. The stained SW1116 cells, but not the HT29 and DLD1 cell lines included a group of about $10.26 \%$ cells negative for both CD133 and EpCAM (Figure 1 and Figure 2A). With regards to EpCAM alone, a large percentage of cells expressed this epitope; approximately $87.30 \%$ of SW 1116 cells, $94.30 \%$ of HT29 cells and $89.30 \%$ of DLD 1 cells (Figure 2B). In assessing CD133 expression, CD133 positive cells also expressed EpCAM in each cell line (Figure 1 and Figure 2C). Moreover, the proportion of CD133 and EpCAM antigen co-expressing cells increased in the respective cell lines, which represent progressive stages of colorectal tumours; within the SW1116 cell line, about $2.42 \%$ of cells were $\mathrm{CD} 133^{+} \mathrm{EpCAM}^{+}$, in the HT29 cell line, $5.13 \%$ of cells were $\mathrm{CD}_{133}{ }^{+} \mathrm{EpCAM}^{+}$, whilst within the DLD1 cell line, $10.30 \%$ of the cells were $\mathrm{CD}_{133^{+}} \mathrm{EpCAM}^{+}$(Figure 2C).

\section{Discussion}

In this study, the co-expression of the CD133 (AC133) and EpCAM epitopes identified a potential CSC population in each of the SW1116, HT29 and DLD1 colorectal adenocarcinoma cell lines. A combination of both markers may distinguish CSCs that are more tumourigenic, and supports the likelihood that these cells are CSCs. Here, we report an increase in the frequency of the CD133/EpCAM CSC population from early to mid- and late stage adenocarcinomas (stages I to III) (Figure 2C). More specifically, there was a two-fold increase in CD133/EpCAM positive cell frequencies in the stage II derived HT29 cell line, when compared to the stage I sourced SW1116 cells. Within the DLD1 stage III cell population, there was a two-fold increase in cells co-expressing CD133/EpCAM in contrast to the HT29 cell line, and a four-fold increase, relative to the SW1116 cell line. From our in vitro study, it would seem that raised proportions of CSCs are associated with increasing tumour grade and may be an important prognostic factor [21].

Both CD133 and EpCAM are associated with poor patient prognosis. Shimada et al. [22] noted a significant correlation between increased CD133 mRNA expression levels and tumour stage, where patients with either stage II or stage III colorectal cancer had both poorer disease free and overall survival than in CD133 negative patients. More recently, raised CD133 levels were reported as a significant predictor for poor disease-free survival and for overall survival in stage II colorectal cancer [23]. In addition, tumour cells expressing EpCAM have been observed to proliferate more rapidly, to grow in an anchorageindependent manner, and also have a reduced requirement for growth factors $[24,25]$. While the role of CD133 is unclear, it does interact in a regulatory signalling complex with histone deacetylase 6 (HDAC6) and $\beta$-catenin in colon and ovarian carcinomas [26]. Targeting of HDAC6 expression or its activity, diminished CD133 signalling, leading to reduced tumourigenesis and increased cell death in colon and ovarian adenocarcinomas. In conclusion, the association of CD133 and EpCAM with the Wnt pathway, their seemingly functional roles in neoplasia, together with their raised frequency with tumour grade as showed here, makes for promising therapeutic targets.

\section{Acknowledgements}

This work was supported by a grant from the Cancer Association of South Africa (CANSA) (CP). Support of the National Research Foundation (NRF) of South Africa and the Faculty Research Committee, Faculty of Health Sciences, University of the Witwatersrand are gratefully acknowledged (BM).

\section{Ethics}

An ethics waiver for cell culture was granted by the Human Research Ethics Committee, University of the Witwatersrand, Reference: W-CJ-090317-3.

\section{References}

1. Jemal A, Bray F, Center MM, Ferlay J, Ward E, et al. (2011) Global cancer statistics. CA Cancer J Clin 61: 69-90.

2. O'Brien CA, Pollett A, Gallinger S, Dick JE (2007) A human colon cancer cell capable of initiating tumour growth in immunodeficient mice. Nature 445: 106110.

3. Ricci-Vitiani L, Lombardi DG, Pilozzi E, Biffoni M, Todaro M, et al. (2007) Identification and expansion of human colon-cancer-initiating cells. Nature 445 : 111-115.

4. Vermeulen L, Sprick MR, Kemper K, Stassi G, Medema JP (2008) Cancer stem cells--old concepts, new insights. Cell Death Differ 15: 947-958.

5. Klonisch T, Wiechec E, Hombach-Klonisch S, Ande SR, Wesselborg S, et al (2008) Cancer stem cell markers in common cancers - therapeutic implications. Trends Mol Med 14: 450-460.

6. Singh SK, Clarke ID, Terasaki M, Bonn VE, Hawkins C, et al. (2003) Identification of a cancer stem cell in human brain tumors. Cancer Res 63: 5821-5828. 
Citation: Milner BL, Penny CB, Gibbon VE, Kay P, Ruff P (2014) CD133/EpCAM Cancer Stem Cell Markers of Tumour Stage in Colorectal Cancer Cells. J Tissue Sci Eng 6: 143. doi:10.4172/2157-7552.1000143

Page 4 of 4

7. Dalerba P, Dylla SJ, Park IK, Liu R, Wang X, et al. (2007) Phenotypic characterization of human colorectal cancer stem cells. Proc Natl Acad Sci U S A 104: 10158-10163.

8. Ferrandina G, Petrillo M, Bonanno G, Scambia G (2009) Targeting CD133 antigen in cancer. Expert Opin Ther Targets 13: 823-837.

9. Weigmann A, Corbeil D, Hellwig A, Huttner WB (1997) Prominin, a nove microvilli-specific polytopic membrane protein of the apical surface of epithelia cells, is targeted to plasmalemmal protrusions of non-epithelial cells. Proc Nat Acad Sci U S A 94: 12425-12430.

10. Yin AH, Miraglia S, Zanjani ED, Almeida-Porada G, Ogawa M, et al. (1997) AC133, a novel marker for human hematopoietic stem and progenitor cells. Blood 90: 5002-5012.

11. Corbeil D, Röper K, Fargeas CA, Joester A, Huttner WB (2001) Prominin: a story of cholesterol, plasma membrane protrusions and human pathology. Traffic 2: 82-91.

12. Bourseau-Guilmain E, Griveau A, Benoit JP, Garcion E (2011) The importance of the stem cell marker prominin-1/CD133 in the uptake of transferrin and in iron metabolism in human colon cancer Caco-2 cells. PLoS One 6: e25515.

13. Balzar M, Briaire-de Bruijn IH, Rees-Bakker HA, Prins FA, Helfrich W, et al. (2001) Epidermal growth factor-like repeats mediate lateral and reciprocal interactions of Ep-CAM molecules in homophilic adhesions. Mol Cell Biol 21 : 2570-2580.

14. Herlyn M, Steplewski Z, Herlyn D, Koprowski H (1979) Colorectal carcinomaspecific antigen: detection by means of monoclonal antibodies. Proc Natl Acad Sci U S A 76: 1438-1442.

15. Litvinov SV, Balzar M, Winter MJ, Bakker HA, Briaire-de Bruijn IH, et al. (1997) Epithelial cell adhesion molecule (Ep-CAM) modulates cell-cell interactions mediated by classic cadherins. J Cell Biol 139: 1337-1348.

16. Münz M, Kieu C, Mack B, Schmitt B, Zeidler R, et al. (2004) The carcinoma- associated antigen EpCAM upregulates c-myc and induces cell proliferation. Oncogene 23: 5748-5758.

17. Catalano V, Di Franco S, lovino F, Dieli F, Stassi G, et al. (2012) CD133 as a target for colon cancer. Expert Opin Ther Targets 16: 259-267.

18. Huet C, Sahuquillo-Merino C, Coudrier E, Louvard D (1987) Absorptive and mucus-secreting subclones isolated from a multipotent intestinal cell line (HT29) provide new models for cell polarity and terminal differentiation. J Cell Biol 105: 345-357.

19. Groden J, Joslyn G, Samowitz W, Jones D, Bhattacharyya N, et al. (1995) Response of colon cancer cell lines to the introduction of APC, a colon-specific tumor suppressor gene. Cancer Res 55: 1531-1539.

20. Kemper K, Sprick MR, de Bree M, Scopelliti A, Vermeulen L, et al. (2010) The AC133 epitope, but not the CD133 protein, is lost upon cancer stem cell differentiation. Cancer Res 70: 719-729.

21. Penny CB, Milner BL, Gibbon VE, Ruff $P$ (2013) The HT29 and DLD-1 colon cancer cell lines contain cancer stem cells. Clin Anat 26: 653.

22. Shimada $R$, linuma $H$, Akahane T, Horiuchi A, Watanabe T (2012) Prognostic significance of CTCs and CSCs of tumor drainage vein blood in Dukes' stage B and C colorectal cancer patients. Oncol Rep 27: 947-953.

23. Ying X, Wu J, Meng X, Zuo Y, Xia Q, et al. (2013) AC133 expression associated with poor prognosis in stage II colorectal cancer. Med Oncol 30: 356.

24. Carpenter G, Red Brewer M (2009) EpCAM: another surface-to-nucleus missile. Cancer Cell 15: 165-166.

25. Maetzel D, Denzel S, Mack B, Canis M, Went P, et al. (2009) Nuclear signalling by tumour-associated antigen EpCAM. Nat Cell Biol 11: 162-171.

26. Mak AB, Nixon AM, Kittanakom S, Stewart JM, Chen GI, et al. (2012) Regulation of CD133 by HDAC6 promotes $\beta$-catenin signaling to suppress cancer cell differentiation. Cell Rep 2: 951-963. 